\title{
Pengaruh Self-care Terhadap Kadar Glukosa Darah Puasa Pasien Diabetes Melitus Tipe-2
}

\author{
Impact Self-care to Fasting Blood Glucose in Patients with Type 2 Diabetes Mellitus
}

\author{
Syahrizal Ramadhani ${ }^{1 *}$, Arie Firdiawan ${ }^{1}$, Tri Murti Andayani ${ }^{2}$, Dwi Endarti ${ }^{2}$ \\ 1. Program Studi Magister Farmasi Klinik, Fakultas Farmasi, Universitas Gadjah Mada \\ 2. Fakultas Farmasi, Universitas Gadjah Mada \\ Submitted: 27-03-2019 Revised: 19-06-2019 Accepted: 19-06-2019 \\ Korespondensi : Syahrizal Ramadhani : Email : syahrizalRamadhani08@gmail.com
}

\begin{abstract}
ABSTRAK
Diabetes Mellitus (DM) adalah keadaan hiperglikemi kronik dimana dapat mempengaruhi seluruh aspek kehidupan penderitanya sehingga dapat mengancam jiwa. Masalah tersebut dapat diminimalkan dengan adanya pengelolaan terhadap DM yaitu dengan cara melakukan self-care. Self-care mempunyai pengaruh terhadap kontrol kadar glukosa darah, pencegahan komplikasi akibat kadar gula darah yang tidak terkontrol dan peningkatan kualitas hidup penderita diabetes mellitus. Penelitian ini bertujuan untuk mengetahui pengaruh self-care terhadap kadar glukosa puasa penderita diabetes tipe 2 . Jenis penelitian ini adalah observasional dengan rancangan cross-sectional. Kriteria inklusi penelitian adalah pasien dengan diagnosa diabetes mellitus berusia $>18$ tahun, berobat di puskesmas $>8$ minggu, terdapat catatan kadar gula darah puasa terakhir $\leq 1$ bulan sebelum wawancara dilakukan, kriteria eksklusi adalah pasien yang menolak untuk berpartisipasi dan pasien yang tidak dapat berkomunikasi. Pengukuran selfcare menggunakan instrument Diabetes Self-Care Management Quesstionaire (DSMQ). Hasil: Jumlah responden dari penelitian ini 115 orang dimana 79,1\% dari responden memiliki tingkat self-care yang baik dan $47 \%$ responden dengan kadar glukosa puasa yang belum tercapai. Data dianalisis menggunakan uji Chi-square, dari hasil analisis menunjukkan bahwa self-care berpengaruh terhadap kadar glukosa puasa $(\mathrm{OR}=3,349, \mathrm{P}<0,05)$. Domain self-care dengan nilai terendah pada penelitian ini adalah domain aktivitas fisik dan health-care, sehingga motivasi pasien perlu ditingkatkan untuk berolahraga dan rutin memeriksakan penyakitnya karena self-care adalah salah satu faktor penting untuk dapat mengontrol kadar glukosa darah.

Kata kunci: Self-care, kadar glukosa darah puasa, DSMQ, diabetes mellitus.
\end{abstract}

\section{ABSTRACT}

Diabetes Mellitus (DM) is a chronic hyperglycemic condition which may affect all aspects of life of the sufferer, and it can be life threatening. This problem can be minimized by doing self-care. Self-care has an influence on glycemic control, prevention of complications due to uncontrolled blood glucose and improving the quality of life for people with diabetes mellitus. This study aimed to determine the effect of self-care on fasting blood glucose of type 2 diabetics. This type of research was observational with cross-sectional design. The inclusion criteria for the study were patients with a diagnosis of diabetes mellitus aged $>18$-year-old, treatment at a health center $>8$ weeks, had records of the last blood glucose fasting $\leq 1$ month before the interview, while the exclusion criteria were patients who refused to participate and patients who could not communicate. Self-care measurement uses the Diabetes Self-Care Management Question (DSMQ) instrument. The number of respondents from this study was 115 people where $79,1 \%$ of respondents had a good level of self-care and $47 \%$ of respondents with fasting glucose levels that had not been achieved. The data were analyzed using Chi-square test. From this study, it was found that self-care had an effect on fasting blood glucose $(O R=3,349, P<0,05)$. The lowest value of selfcare in this study is the domain of physical activity and health-care, therefore patient motivation needs to be improved by exercise and routine check-up because self-care is one of the important factors that could control blood glucose levels.

Keywords: Self-care, fasting blood glucose, DSMQ, Diabetes Mellitus.

\section{PENDAHULUAN}

Diabetes adalah masalah kesehatan yang serius, menurut IDF tahun 2017 prevalensi diabetes secara global adalah $8,8 \%$ atau 424,9 juta penderita dengan angka kematian 4 juta jiwa penduduk dunia dan 
diperkirakan pada tahun 2045 prevalensi penderita diabetes akan meningkat menjadi $9,9 \%$ atau 628,6 juta jiwa. Prevalensi diabetes di Indonesia menurut riset kesehatan dasar adalah 2,1\% dimana Yogyakarta menempati urutan pertama pada prevalensi diabetes yang terdiagnosis diabetes yaitu sebesar 2,6\%1. Menurut dinas kesehatan kabupaten Bantul pada tahun 2016 diabetes menempati urutan ke-4 pada 10 penyakit terbesar sekabupaten Bantul2.

Diabetes melitus adalah penyakit kronis dimana diperlukan terapi berkesinambungan untuk dapat mengontrol kadar glukosa dengan baik, selain terapi farmakologi juga diperlukan terapi nonfarmakologi untuk memaksimalkan kontrol glukosa darah termasuk juga dalam hal ini adalah tindakan self-care. Self-care adalah tindakan yang dilakukan untuk merawat diri sendiri secara mandiri dengan cara meningkatkan pengetahuan dan kewaspadaan terhadap penyakit untuk dapat mengontrol kadar glukosa darah dengan baik, mencegah terjadi komplikasi dan meningkatkan kualitas hidup ${ }^{3}$.Self-care dapat membantu mencapai $\mathrm{HbA1c}$ sesuai target dan memperpendek lama rawat di rumah sakit serta meningkatkan kualitas hidup penderita diabetes ${ }^{4,5}$.

Self-care dapat dinilai dengan menggunakan kuesioner salah satunya adalah The Diabetes Self-management Questionnaire (DSMQ) yang merupakan pengembangan SDSCA. DSMQ mempunyai korelasi lebih baik terhadap $\mathrm{HbA1c}$ dibandingkan dengan SDSCA dan DSMQ lebih relevan dan reliabel menggambarkan hubungan antara self-care dan kadar glukosa darah ${ }^{6}$. Penelitian ini menggunakan kuesioner DSMQ yang mana kuesioner DSMQ belum pernah digunakan di Indonesia sebelumnya.

Menurut penelitian yang dilakukan sebelumnya yang mengevaluasi hubungan antara self-care terhadap $\mathrm{HbA1c}$ menggunakan kuesioner DSMQ menunjukkan adanya hubungan yang signifikan antara self-care dan $\mathrm{HbA1}^{4,6,8,9}$. Namun hubungan self-care terhadap kadar glukosa darah puasa menggunakan kuesioner DSMQ dibeberapa penelitian menunjukkan hasil yang berbedabeda, terdapat penelitian yang menunjukkan bahwa self-care mempunyai hubungan signifikan terhadap kadar glukosa darah puasa7. Terdapat penelitian lain menunjukkan hubungan tidak signifikan antara self-care dan kadar glukosa darah puasa ${ }^{10}$. Oleh karena penelitian ini bertujuan untuk mengetahui hubungan antara self-care yang diukur menggunakan kuesioner DSMQ terhadap kadar glukosa darah puasa pada penderita diabetes tipe 2 .

\section{METODE}

Penelitian ini bersifat observasional menggunakan rancangan cross-sectional study dengan menggunakan survey kuesioner. Penelitian dilakukan di 2 puskesmas, yaitu 1 puskesmas daerah Yogyakarta dan 1 puskesmas di daerah Bantul pada bulan Oktober-Desember 2018. Perhitungan jumlah sampel menggunakan rumus korelasi dengan $\mathrm{Z} \alpha$ 5\% (1,64), Z $\beta$ 10\% $(1,28)$ dan $\mathrm{r}-0,302^{11}$ sehingga diperoleh jumlah sampel minimal 87 responden .Jumlah responden pada penelitian ini adalah sebanyak 115 orang dan telah representatif untuk menggambarkan hubungan antara self-care terhadap kadar glukosa darah puasa. Kriteria inklusi adalah pasien yang didiagnosa diabetes mellitus tipe 2 berusia $>18$ tahun, rutin berobat ke puskesmas lebih dari 8 minggu, terdapat hasil laboratorium yang menunjukkan kadar glukosa terakhir paling tidak 1 bulan sebelum wawancara dilakukan. Kriteria eksklusi adalah pasien yang menolak berpartisipasi dan tidak dapat berkomunikasi.Penelitian ini sudah diberikan izin oleh komisi etik dengan no KE/FK/0930/EC/2018.

\section{Pengumpulan sampel}

Pengambilan sampel dilakukan langsung pada satu waktu menggunakan metode accidental sampling. Terdapat dua kali pengambilan data, data pertama diperoleh dengan melakukan wawancara untuk mengetahui data sosiodemografi responden berupa usia, jenis kelamin, tingkat 
pendidikan, pendapatan, lama menderita diabetes, dan komplikasi penyakit. Responden yang setuju mengikuti penelitian selanjutnya menandatangani inform consent kemudian mengisi kuesioner self-care. pengambilan data kedua melalui rekam medik untuk mengumpulkan data kadar glukosa darah puasa, komplikasi, dan komorbid.

\section{Alat ukur}

Self-care

Alat yang digunakan untuk mengukur self-care pada penelitian ini adalah The Diabetes Self-Management (DSMQ). DSMQ tersedia dalam Bahasa Inggris dan belum tersedia dalam Bahasa Indonesia. Kuesioner ditranslasikan dari Bahasa inggris ke Bahasa Indonesia dan dilakukan di Pusat Pelatihan Bahasa Fakultas Ilmu Budaya Universitas Gadjah Mada secara forward dan backward oleh dua native yang berbeda kemudian dilakukan review oleh expert.

DSMQ digunakan untuk mengamati dan mengukur perilaku self-care selama 8 minggu sebelum wawancara dilakukan. DSMQ valid dan reliabel untuk mengukur selfcare dan sebagai alat yang baik untuk memprediksi glycemic outcome ${ }^{6,12}$. Pada penelitian ini dilakukan uji reliabilitas internal consistency dan didapatkan angka koefisien alpha Cronbrach's 0,697. DSMQ terdiri dari 16 pertanyaan dan 4 domain: manajemen glukosa, kontrol diet, aktivitas fisik dan healthcare. Rating scale terdiri dari 4 pilihan yaitu 'sangat sesuai untuk saya' (3 poin), 'cukup sesuai untuk saya' (2 poin), 'sedikit sesuai untuk saya' (1 poin), 'tidak sesuai untuk saya' (0 poin). Nilai self-care diperoleh dengan menjumlahkan total poin pertanyaan dan ditransformasikan kedalam bentuk skala 0-10 (nilai yang didapat / maksimum nilai teori * 10) dimana semakin tinggi nilai maka mengindikasikan semakin efektif self-care ${ }^{9}$. Tingkat self-care dibagi menjadi 2 kelompok, yaitu tingkat self-care buruk $\leq 6$ dan 6-10 tingkat self-care baik ${ }^{13}$.

\section{Analisis statistik}

Penelitian ini menggunakan rancangan cross-sectional study. Data sosiodemografi dianalisis secara deskriptif. Hubungan antara self-care dan kadar glukosa darah puasa dianalisis menggunakan Chi-square. Uji statistik pada penelitian ini menggunakan software Statistical Package for the Social Science (SPSS) versi 23.

\section{HASIL DAN PEMBAHASAN \\ Sosiodemografi responden}

Jumlah responden yang ikut berpartisipasi dalam penelitian ini adalah 115 orang. Data karakteristik dari responden (Tabel I). Sebanyak 77\% responden adalah wanita dansebanyak $58,3 \%$ responden berusia lebih dari 60 tahunhasil penelitian ini sama dengan penelitian sebelumnya ${ }^{8,14-17}$ dan peneltian yang dilakukan oleh Kakade dkk yang menunjukkan jumlah responden didominasi oleh responden usia $>60$ tahun $^{18}$. Penderita diabetes usia lanjut melakukan olahraga lebih jarang daripada penderita dewasa, hal ini disebabkan penderita diabetes usia lanjut umumnya terjadi komplikasi dan memiliki penyakit kronis lain sehingga sulit bagi mereka untuk melakukan self-care seperti beraktifitas fisik ${ }^{16}$, hal tersebut menyebabkan peningkatan berat badan dan perkembangan penyakit diabetes ${ }^{19}$.

Responden yang mempunyai tingkat pendidikan tinggi sebesar $7 \%$ yang didominasi tingkat pendidikan sedang (SMP / SMA) yaitu 51,3\% sejalan dengan penelitian sebelumnya ${ }^{18}$. Status ekonomi responden didominasi ekonomi rendah sebesar 41,7\% dimana status ekonomi sangat tinggi sebesar $5,2 \%$ proporsi ini mirip dengan penelitian lain $^{19,20}$. Status ekonomi yang rendah dapat menyebabkan resiko kontrol glikemik yang buruk hal ini disebabkan ketidakmampuan untuk membeli makanan yang sehat, kemampuan, menyebabkan stres yang memicu peningkatan berat badan, keinginan merokok dan konsumsi alkohol yang dapat menyebabkan perkembangan komplikasi diabetes $^{21}$.

Responden durasi DM $<5$ tahun sebesar $53,9 \%$ dan $>10$ tahun sebesar $14,8 \%$ hasil ini mirip dengan penelitian sebelumnya $15,16,18,20$ dan sedikit berbeda dengan beberapa penelitian lain dimana di dominasi responden 
Syahrizal Ramadhani, et al

Tabel I. Sosiodemografi Pasien Diabetes Melitus Tipe 2

\begin{tabular}{lcc}
\hline \multicolumn{1}{c}{ Karakteristik } & $\begin{array}{c}\text { Jumlah subjek (n=115) } \\
\text { Atau rata-rata }\end{array}$ & $\begin{array}{c}\text { Persentase } \\
\mathbf{( \% )}\end{array}$ \\
\hline Jenis kelamin & 26 & 23 \\
$\quad$ Laki-laki & 87 & 77 \\
$\quad$ Wanita & & \\
Usia & 48 & 41,7 \\
$\quad 18$ - 59 tahun & 67 & 58,3 \\
$\quad$ 60 tahun & & \\
Tingkat Pendidikan & 48 & 41,7 \\
$\quad$ Rendah (Tidak bersekolah/ SD) & 59 & 51,3 \\
$\quad$ Sedang (SMP/ SMA) & 8 & 7 \\
$\quad$ Tinggi (Perguruan tinggi) & & \\
Status Ekonomi & 65 & 56,5 \\
$\quad$ Rendah (<Rp. 1.500.000) & 36 & 31,3 \\
$\quad$ Sedang (Rp. 1.500.000-2.499.900) & 8 & 7 \\
$\quad$ Tinggi (Rp.2.500.000- 3.500.000) & 6 & 5,2 \\
$\quad$ Sangat tinggi (>Rp3.500.000) & & \\
Durasi penyakit DM & 62 & 53,9 \\
$\quad$ < tahun & 36 & 31,3 \\
5-10 tahun & 17 & 14,8 \\
$\quad$ 10 tahun & & 4,3 \\
Komplikasi penyakit & 5 & 95,7 \\
$\quad$ Dengan komplikasi & 110 &
\end{tabular}

dengan durasi DM 5-10 tahun $^{22}$ dan $>10$ tahun ${ }^{13,23}$. Responden dengan komplikasi pada penelitian ini sebesar $4,3 \%$ dan tanpa komplikasi sebesar 95,7\% (tabel 1), berbeda dengan penelitian Gao dkk dimana responden sebanyak $69,8 \%$ mempunyai komplikasi ${ }^{8}$. Hal ini disebabkan penelitian dilakukan di puskesmas dimana pada umumnya pasien baru terdiagnosa diabetes dan belum terjadi komplikasi. Durasi penyakit diabetes berhubungan dengan kadar glukosa darah dan angka kejadian komplikasi. Pada penelitian yang dilakukan oleh Zoungas dkk peningkatan durasi diabetes dalam 5 tahun menyebabkan peningkatan kadar glukosa darah dan angka kejadian komplikasi secara signifikan ${ }^{24}$.

Hubungan self-care dan kadar glukosa darah puasa

Self-care adalah salah satu faktor yang krusial dalam manajemen penyakit diabetes dimana self-care yang efektif pada jangka panjang dapat memperbaiki status klinik (kadar glukosa, tekanan darah, dan kolestrol), status kesehatan (mengurangi resiko komplikasi), dan meningkatkan kualitas hidup ${ }^{18}$. Salah satu alat untuk mengukur efektifitas self-care adalah The Diabetes Self-management Questionnaire (DSMQ) yang dikembangkan oleh Schmit dkk untuk mengukur efektifitas self-care serta sebagai salah satu predictor terhadap outcome klinik yaitu kadar glukosa darah", DSMQ juga dapat dipakai untuk mengetahui penyebabkan terjadinya hiperglikemik dengan cara mengevaluasi perilaku self-care pasien ${ }^{12}$.

Penelitian ini dilakukan untuk mengetahui hubungan self-care dengan kadar glukosa puasa penderita diabetes mellitus tipe 2. Pada penelitian yang mengamati tentang hubungan antara self-care dengan $\mathrm{HbA1c}$ dan kadar glukosa darah puasa menunjukkan 
Tabel II. Hubungan Antara Self-care Terhadap Kadar Glukosa Darah Puasa

\begin{tabular}{cccccc}
\hline \multirow{2}{*}{$\begin{array}{c}\text { Perilaku } \\
\text { self-care }\end{array}$} & N (\%) & $\begin{array}{c}\text { Tercapai } \\
(80-130 \mathrm{mg} / \mathrm{dL})\end{array}$ & $\begin{array}{c}\text { Tidak tercapai } \\
(>130 \mathrm{mg} / \mathrm{dL})\end{array}$ & OR $(95 \% \mathrm{CI})$ & Nilai P \\
\cline { 3 - 5 } Total & $\mathbf{1 1 5}(\mathbf{1 0 0 )}$ & $61(53 \%)$ & $54(47 \%)$ & & \\
\hline Baik & $91(79,1 \%)$ & 48 & 43 & 3,349 & $0,021^{*}$ \\
Buruk & $24(20,9 \%)$ & 6 & 18 & $(1,218-9,028)$ & \\
\hline
\end{tabular}

Keterangan: analisis Chi-square; OR (Odds Ratio); CI (Confidence Interval) ; *signifikan secara statistik $(<0,05)$

korelasi negative dimana semakin efektif selfcare maka semakin rendah $\mathrm{HbA1c}$ dan kadar glukosa darah puasa', ${ }^{9}$. Semakin efektif selfcare maka kadar glukosa juga akan semakin terkontrol hal ini dibuktikan pada penelitian sebelumnya dimana pasien dengan kontrol glikemik yang baik mempunyai tingkat 'manajemen glukosa; kontrol diet; aktifitas fisik; dan health-care yang lebih tinggi dibandingkan pada pasien dengan kontrol glikemik yang buruk9.

Rata-rata kadar glukosa puasa responden adalah 156,87 mg/dL (tabel II) yang menunjukkan bahwa kadar glukosa puasa belum terkontrol dengam optimal, hasil ini mirip dengan penelitian sebelumnya ${ }^{25,26}$. Ratarata kadar glukosa puasa penelitian ini lebih rendah daripada penelitian yang dilakukan oleh Tegegne dkk, hal ini mungkin disebabkan tingkat self-careyang tidak adekuat pada penelitian tersebut sehingga mempunyai ratarata kadar glukosa darah puasa yang tinggi ${ }^{27}$.

Pada penelitian ini self-care berpengaruh terhadap kadar glukosa darah puasa $(\mathrm{P}<0,05)$, dimana pasien dengan tingkat self-care baik 3,349 kali memiliki kontrol glukosa yang baik dibandingkan pasien dengan tingkat self-care yang buruk. Hasil ini mirip dengan penelitian yang dilakukan oleh Navicharern dkk yang menunjukkan terdapat hubungan yang signifikan antara self-care dengan kadar glukosa darah puasa ${ }^{23}$ dan penelitian lain yang menunjukkan hubungan yang signifikan antara self-care dan $\mathrm{HbA1} \mathrm{c}^{6,12,17}$. Berbeda dengan penelitian yang dilakukan oleh Babatunde dkk dimana tidak terdapat hubungan yang signifikan antara self-care dan kadar glukosa puasa28.

Kuesioner DSMQ terdiri dari 4 domain yang didesain berdasarkan item pertanyaan yang mempunyai korelasi yang baik terhadap kadar glukosa darah sehingga dapat menjadi alat ukur yang valid untuk dapat memprediksi hubungan antara self-care dengan kadar glukosa darah'. Penelitian ini menunjukkan domain kontrol diet $(\mathrm{P}=0,014)$ dan aktifitas fisik $(\mathrm{P}=0,009)$ signifikan terhadap kadar glukosa puasa namun healthcare $(\mathrm{P}=0,322)$ dan manajemen glukosa $(\mathrm{P}=0,230)$ tidak berhubungan signifikan (tabel II). Hasil ini mirip dengan penelitian sebelumnya dimana domain health-care ${ }^{17}$ dan manajemen glukosa ${ }^{29}$ tidak mempunyai hubungan signifikan terhadap kadar glukosa darah. Berbeda dengan penelitian original DSMQ yang menunjukkan hubungan yang signifikan antara kadar glukosa dengan 4 domain self-care yaitu manajemen glukosa, kontrol diet, aktifitas fisik dan health-care ${ }^{6,12}$. Perbedaan ini mungkin disebabkan sociodemografi, budaya, dan fasilitas kesehatan yang berbeda antar negara.

Pada (Tabel III) menunjukkan 2 domain dengan mean score yang paling rendah adalah domain aktivitas fisik dan domain health-care, hasil ini mempunyai proporsi yang sama dengan penelitian yang dilakukan sebelumnya dimana mean score domain aktifitas fisik dan domain health-care adalah domain dengan mean score terendah ${ }^{13,28}$. Hal ini menjadi perhatian untuk tenaga kesehatan dalam manajemen pengobatan diabetes tipe 2 
Syahrizal Ramadhani, et al

Tabel III. Hubungan Domain Self-care dan Kadar Glukosa Darah Puasa pada Penderita Diabetes Tipe 2

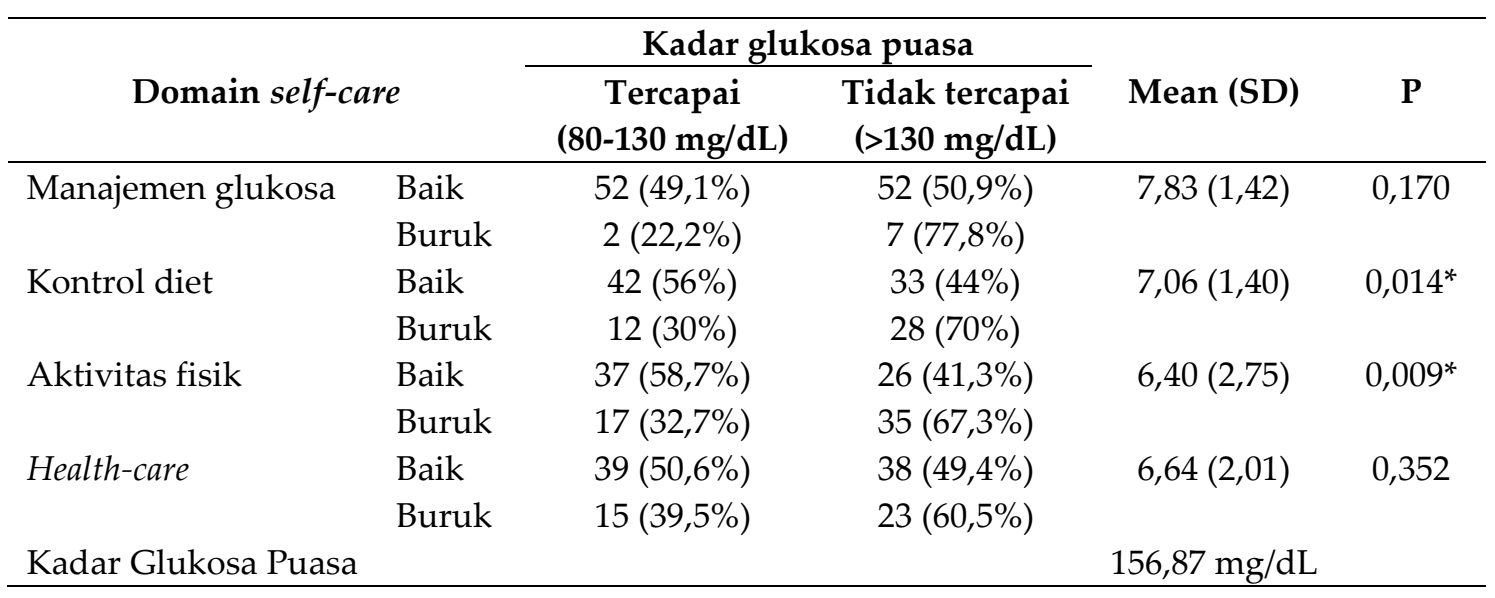

Keterangan: analisis Chi-square; ${ }^{*}$ signifikan secara statistik $(<0,05)$

untuk meningkatkan kepatuhan pasien rutin kontrol memeriksakan penyakitnya serta meningkatkan aktivitas fisik atau olahraga karena aktivitas fisik berhubungan dengan kontrol glikemik yang baik, angka kejadian komplikasi yang lebih rendah, dan kualitas hidup yang lebih baik ${ }^{4}$.

Responden mayoritas memiliki tingkat self-care yang baik yaitu sebesar $79,1 \%$ namun $47 \%$ dari seluruh responden mempunyai outcome klinik yang belum tercapai,(tabel III) hal ini dikarenakan self-care hanya salah satu faktor yang dapat mempengaruhi kadar glukosa darah, banyak faktor lain yang mempengaruhi dan berhubungan dengan kadar glukosa darah seperti tingkat pengetahuan terhadap penyakit diabetes ${ }^{30}$, stress $^{31}$, durasi puasa sebelum test kadar glukosa darah puasa ${ }^{32}$, dan pemilihan obat ${ }^{33}$. Faktor-faktor lain tersebut tidak diukur dan menjadi keterbatasan pada penelitian ini.

\section{KESIMPULAN}

Self-care berpengaruh terhadap kadar glukosa darah puasa penderita diabetes tipe 2 $(\mathrm{OR}=3,349, \mathrm{P}=0,021)$. Domain self-care terendah adalah domain aktivitas fisik dan health-care sehingga menjadi tantangan bagi tenaga kesehatan untuk dapat meningkatkan motivasi pasien melakukan manajemen penyakit diabetes khususnya melakukan olahraga dan kontrol rutin ke dokter.

\section{DAFTAR PUSTAKA}

1. Riset Kesehatan Dasar., 2013. Riset kesehatan Dasar. 2013. Badan penelitian dan pengembangan kementrian kesehatan RI tahun 2013.

2. Dinas Kesehatan Bantul., 2016. Dinas Kesehatan Bantul., 2016, Profil Kesehatan Kota Yogyakarta Tahun 2012, Dinas Kesehatan Yogyakarta, Yogyakarta..pdf.

3. Shrivastava S., Shrivastava P., Ramasamy J. Role of self-care in management of diabetes mellitus. $J$ Diabetes Metab Disord. 2013;12(1):14.

4. Ausili D., Bulgheroni M., Ballatore P., et al., Self-care, quality of life and clinical outcomes of type 2 diabetes patients: an observational cross-sectional study. Acta Diabetol. 2017;54(11):1001-1008.

5. Song M., Ratcliffe SJ., Tkacs NC., Riegel B. Self-Care and Health Outcomes of Diabetes Mellitus. Clin Nurs Res. 2012;21(3):309-326.

6. Schmitt A., Gahr A., Hermanns N., Kulzer B., Huber J., Haak T. The Diabetes Self-Management Questionnaire (DSMQ): development 
and evaluation of an instrument to assess diabetes self-care activities associated with glycaemic control. Health Qual Life Outcomes. 2013;11(1):138.

7. Navicharern R. Diabetes SelfManagement, Fasting Blood Sugar and Quality of Life among Type 2 Diabetic Patients with Foot Ulcers. 2012;95(2):7. doi:

8. Gao J., Wang J., Zheng P., et al., Effects of self-care, self-efficacy, social support on glycemic control in adults with type 2 diabetes. BMC Fam Pract. 2013;14(1).

9. Kakade A., Mohanty I., Rai S. Assessment of knowledge, attitude and self-care activities among type-2 diabetic patients attending a tertiary care teaching hospital. Int J Basic Clin Pharmacol. 2016:2458-2462.

10. Babatunde S., Onu R. Psychometric Performance of the Diabetes SelfManagement Questionnaire (DSMQ) Among Individuals Attending a Referral Hospital in Port Harcourt, Nigeria. :6.

11. Nurjanah S., Diani N., Rizany I. Hubungan Self Care Dengan Kadar Gula Darah Puasa Pada Pasien Diabetes Melitus Tipe 2 Di Rsud Ulin Banjarmasin. 2018;9(1):15.

12. Schmitt A., Reimer A., Hermanns N., et al., Assessing Diabetes SelfManagement with the Diabetes SelfManagement Questionnaire (DSMQ) Can Help Analyse Behavioural Problems Related to Reduced Glycaemic Control. Wang X, ed. PLOS ONE. 2016;11(3):e0150774.

13. Ang J-Y., Leo J-S., George D., Chan H-K. Inadequate Self-Care Behaviors among Malaysian Diabetic Patients: The Need for Action by Hospital Pharmacists. J Pharm Pract Community Med. 2018;4(2):51-54.

14. Chaidir R., Wahyuni AS.., Furkhani DW. Hubungan Self Care Dengan Kualitas Hidup Pasien Diabetes Melitus. J Endur. 2017;2(2):132.
15. Alrahbi H. Diabetes self-management (DSM) in Omani with type-2 diabetes. Int J Nurs Sci. 2014;1(4):352-359.

16. Rn ZFA., Rn MA. Diabetes Self Care Management Behaviors among Jordanian Type Two Diabetes Patients. 2015;5(3):9.

17. Bukhsh A., Lee SWH., Pusparajah P., Schmitt A., Khan TM. Psychometric properties of the Diabetes SelfManagement Questionnaire (DSMQ) in Urdu. Health Qual Life Outcomes. 2017;15(1).

18. Kakade A., Mohanty I., Rai S. Assessment of knowledge, attitude and self-care activities among type-2 diabetic patients attending a tertiary care teaching hospital. Int J Basic Clin Pharmacol. 2016:2458-2462.

19. Islam MR. Association between SocioDemographic Factors and Blood Sugar Levels in Type 2 Diabetes Mellitus Patients in Bangladesh. J Diabetes Mellit. 2017;07(03):151-159.

20. Lin K., Yang X., Yin G., Lin S. Diabetes Self-Care Activities and Health-Related Quality-of-Life of individuals with Type 1 Diabetes Mellitus in Shantou, China. J Int Med Res. 2016;44(1):147-156.

21. Gonzalez-Zacarias AA., MavarezMartinez A., Arias-Morales CE., Stoicea N., Rogers B. Impact of Demographic, Socioeconomic, and Psychological Factors on Glycemic Self-Management in Adults with Type 2 Diabetes Mellitus. Front Public Health. 2016;4.

22. Babazadeh T., Dianatinasab M., Daemi A., Nikbakht HA., Moradi F., Ghaffarifam S. Association of Self-Care Behaviors and Quality of Life among Patients with Type 2 Diabetes Mellitus: Chaldoran County, Iran. Diabetes Metab J. 2017;41(6):449.

23. Navicharern R. Diabetes SelfManagement, Fasting Blood Sugar and Quality of Life among Type 2 Diabetic Patients with Foot Ulcers. 2012;95(2):7.

24. for the ADVANCE Collaborative group., Zoungas S., Woodward M., 
et al., Impact of age, age at diagnosis and duration of diabetes on the risk of macrovascular and microvascular complications and death in type 2 diabetes. Diabetologia. 2014;57(12):24652474.

25. Nurjanah S., Diani N., Rizany I. Hubungan Self Care Dengan Kadar Gula Darah Puasa Pada Pasien Diabetes Melitus Tipe 2 Di Rsud Ulin Banjarmasin. 2018;9(1):15.

26. Sorato M M., C T. Levels and Predictors of Adherence to Self-care Behaviour among Adult Type 2 Diabetics at Arba Minch General Hospital, Southern Ethiopia. J Diabetes Metab. 2016;7(6).

27. Tegegne GT., Shiferaw A., Gelaw BK. Glycemic Control and Self-Care Practice among Ambulatory Diabetic Patients in Ambo General Hospital, West Showa, Ethiopia. 2014:11.

28. Babatunde S., Onu R. Psychometric Performance of the Diabetes SelfManagement Questionnaire (DSMQ) Among Individuals Attending a Referral Hospital in Port Harcourt, Nigeria. :6.

29. Ouyang C-M., Dwyer JT., Jacques PF.,
Chuang L-M., Haas CF., Weinger K. Diabetes Self-Care Behaviours and Clinical Outcomes among Taiwanese Patients with Type 2 Diabetes. Asia Pac J Clin Nutr. 2015;24(3):438-443.

30. Fenwick EK., Xie J., Rees G., Finger RP., Lamoureux EL. Factors Associated with Knowledge of Diabetes in Patients with Type 2 Diabetes Using the Diabetes Knowledge Test Validated with Rasch Analysis. Khamseh ME, ed. PLoS ONE. 2013;8(12):e80593.

31. Derek Mi., Rottie Jv., Kallo V. Hubungan Tingkat Stres Dengan Kadar Gula Darah Pada Pasien Diabetes Melitus Tipe Ii Di Rumah Sakit Pancaran Kasih Gmim Manado. 2017;5:6.

32. Moebus S., Göres L., Lösch C., Jöckel KH. Impact of time since last caloric intake on blood glucose levels. Eur J Epidemiol. 2011;26(9):719-728.

33. Phung OJ., Sobieraj DM., Engel SS., Rajpathak SN. Early combination therapy for the treatment of type 2 diabetes mellitus: systematic review and meta-analysis. Diabetes Obes Metab. 2014;16(5):410-417.. 